\title{
Comprehensive study of head lice infestation in Mosul primary schools (right and left side)
}

\author{
Khalida Abdulla Sulaiman ${ }^{1 *}$; Aulfat Tahseen Yaseen²; Zena Zakarya Edrees ${ }^{3}$ \\ ${ }^{1,2,3}$ Department of Biology, College of Science, University of Mosul, Mosul, Iraq \\ Email: ${ }^{1 * k a l d a u b d a l l a @ y a h o o . c o m},{ }^{2}$ aulfat.tahseen @yahoo.com, ${ }^{3}$ younisz1993@gmail.com
}

(Received July 31, 2019; Accepted November 17, 2019; Available online March 01, 2020)

DOI: 10.33899/edusj.2019.125926.1010, (c) 2020, College of Education for Pure Science, University of Mosul.

This is an open access article under the CC BY 4.0 license (http://creativecommons.org/licenses/by/4.0/).

\begin{abstract}
The current study of head lice Pediculus humanus capiti, was conducted in 11 primary schools for girls in different social and economic areas of the city of Mosul on its right and left sides for the period from 15 October 2018 to 15 February 2019. The present study showed that the total incidence of head lice in the 5 schools covered by the right city was $27.44 \%$ while the total injury rate in the 6 schools covered by the left city side was $11.13 \%$, the highest percentage of girls with long hair was recorded in the first Zubaidah school on the left side and reached 75\%, and Al- Bashair school in the right side where it reached $83.33 \%$, while the highest percentage of girls with short hair in the school of Genin in the left side at $75 \%$ and on the right side Al-Sajideen and Al-Shaheed Salem schools as the proportion with short hair in which 33.5 and $33.33 \%$ respectively. As for the educational level of mothers of infected girls, the highest rate of infection for mothers of non-educated mothers in the school of Al-Jahafil on the left side of the city, reaching 100\%, while the school Al-Bashair recorded $96 \%$ on the right side of the city. In addition, the percentage of casualties according to the number of family members was the highest rate of injury to families with fewer than 5 members of the school in Al-Foratain school on the left side of the city with $65 \%$, while the highest rate of infection was recorded for families with more than 5 members in Al-Khalidya school, at 85.07\%. As for the schools on the right side of the city, the highest percentage of families with fewer than 5 members in AL-Bashair school was $28 \%$, while the highest percentage was recorded for families with more than 5 members in Al-Sajideen school has reached the percentage of $83 \%$.
\end{abstract}

Key words: Head lice, infestation , Study, Primary school , Mosul

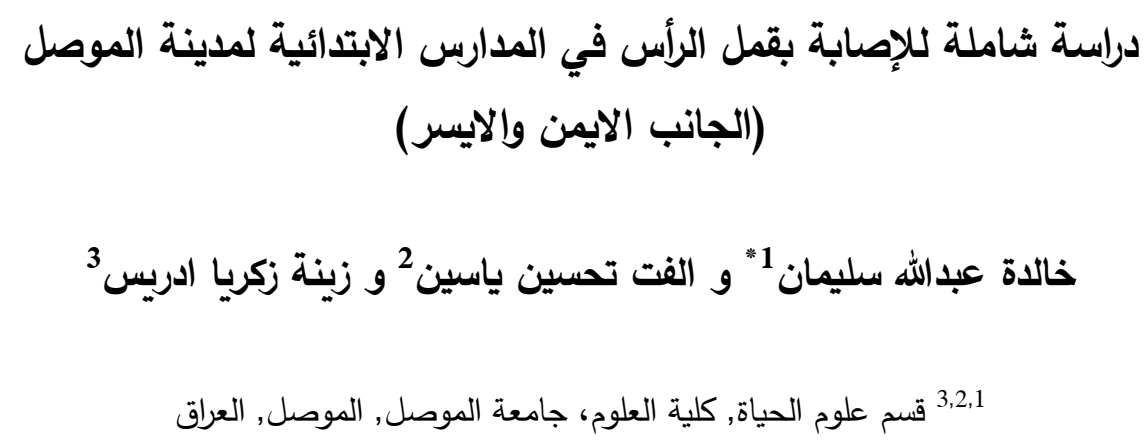


اجريت الدراسـة الحالية للتحري عن قمل الرأس Pediculus humanus capitis في احدى عشـرة مدرســة ابتدائية للبنات في مناطق متباينة بالمستوى الاجتماعي والاقتصادي من مدينة الموصل في جانبيها الايمن والايسر للفترة من 15 تشرين الاول 2018 ولغاية 15 شباط 2019 ـ اظهرت الدراسة الحالية ان نسبة الاصـابة الكلية لقمل الرأس في المدارس الخمسة المشمولة بالدراسة في مالي جانب المدينة الايمن بلغت 27.44\% بينما كانت نسـبة الاصــابة الكلية في المدارس السـتة المشـمولة بالدراسـة في جانب المدينة الايسر 11.13\% ، سجلت اعلى نسبة اصـابة في البنات ذوات الثـعر الطويل في مدرسـة زبيدة الاولى في الجانب الايسر وبلغت

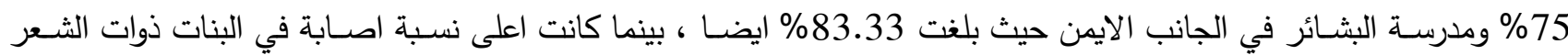
القصير في مدرسـة جنين في الجانب الايسر اذ بلغت 75\% وفي الجانب الايمن مدرسـتي السـاجدين والثــيد سـالم اذ بلغت نسبة المصابات ذوات الثعر القصير فيهما 33.5 و 33.33\% على التوالي ـ اما فيما يخص المستوى التعليمي لأمهات المصـابات فقد

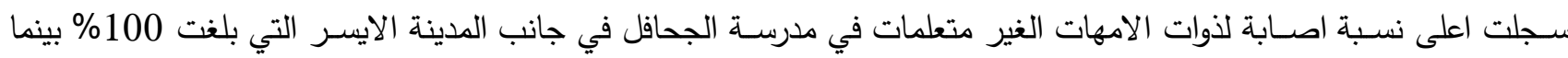

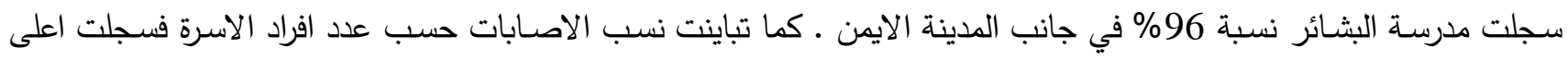

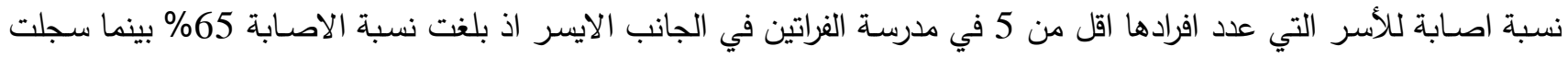

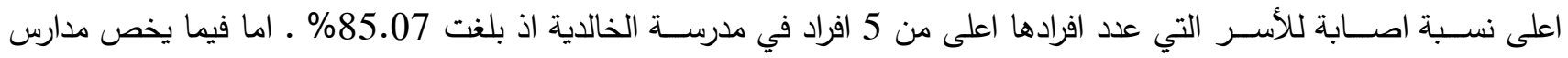

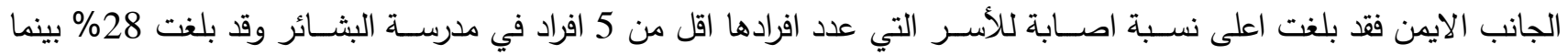

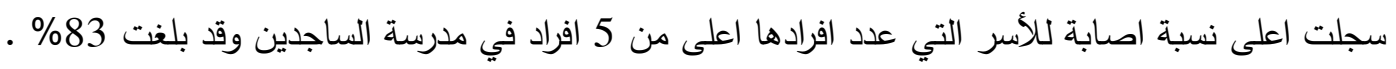

الكلمات المفتاحية: قمل الرأس ، إصابة ، دراسة ، المدارس الابتدائية ، مدينة الموصل

\section{المقدمة}

قمل الانسـان Pediculus humanus capitis هو طفيليات خارجية - اجبارية ماصـة للدم متخصصـة على البثر تعود الى

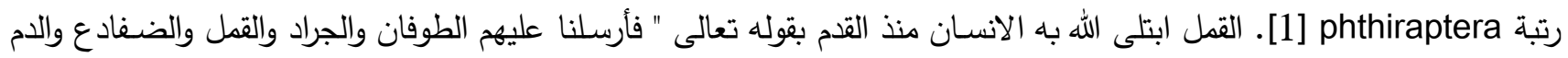
آيات مفصلات فاستكبروا وكانوا قوما مجرمين" سورة الاعراف-آية 133 ـ لايزال المجتمع البشري المعاصر يعاني من ذلك الكئ الطفيلي

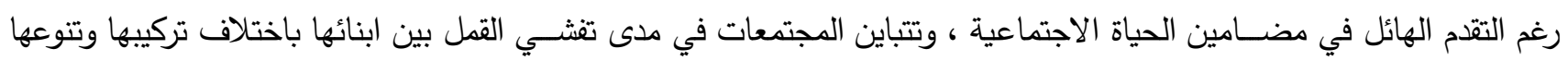

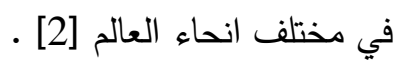
القمل حشرات صغيرة عديمة الاجنحة وتكون اجسامها مضغنوطة من الجهتين الظهرية والبطنية ولها قرون استشعار تتألف من 3-5 قطع كما تمتلك 3 أزواج من الارجل و ينتهي كل زوج بمخلب ولها ايضـا فتحات (ثغور ) تنفسـية تكون ظهرية وجانبية [3] ـ

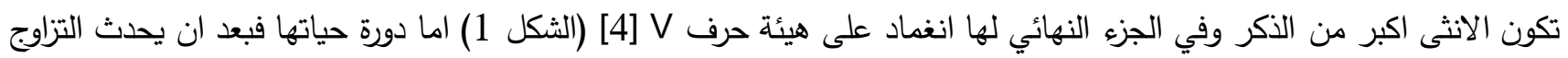
تضع الانثى البيض بعد 1-2 يوم ويعرف

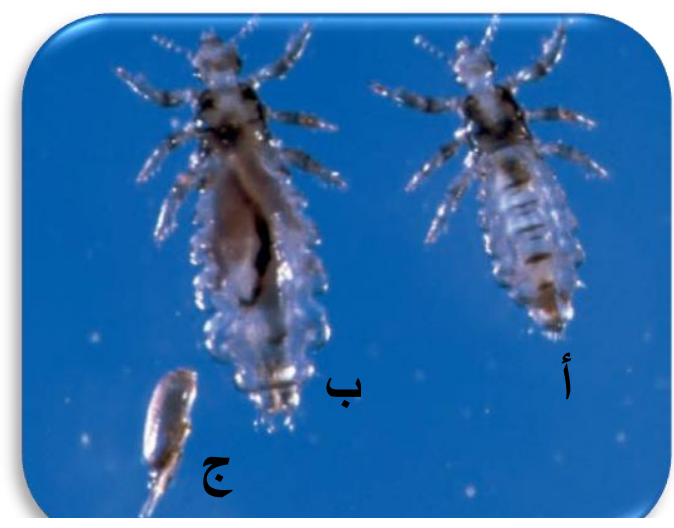

الثكل (1) قمل الوأس أ- الذكر ، ب - الأنثى ج - البيضة 
بالصـبان (Nits) ويكون شكل البيض بيضـوي وتلصـق الانثى بيوضـها بقوة في اماكن معيشتها عند قاعدة الثـعر بواسطة مادة اســنتية تفرزها الاقلام التناسـلية وتضــع الانثى( اربع الى ثمان) بيضـات يوميا وتكون درجة حضــانة البيض قريبة من درجة حرارة الانسان ، بعد ذلك تفقس البيوض الى حوريات وتتغذى على دم العائل ، للحوريات 3 أعمار • تستغرق مدة الجيل في قمل الرأس 3 أسابيع (الثكل 2) [5] .

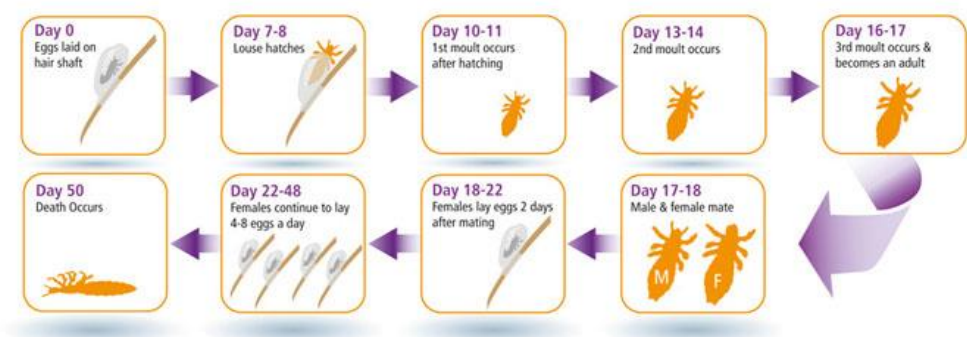

الثكل (2) دورة حياة قمل الرأس

التقميل pediculosis هو وجود قمل الجسم او الرأس او العانة على الثخص وقد يصبح الجلد خشنا ومصبوغا في حالة التقميل الثديد وتعرف هذه الحالة بمرض المتشردين ، وقد تؤدي التأثيرات السـامة لحقن اللعاب بشكل متكرر من قبل الحشرة نتيجة للتغذية المستمرة على العائل الى الثعور بالضجر والاستثارة والكسل وتعكير المزاج وحدوث حساسية مثل الحكة الشديدة [6]. تؤدي الحكة

الى اصابات ثانوية مثل حدوث تهيج الجلد وتورم العقد اللمفاوية المحيطة [7]. ينقل القمل امراضــاً عديدةً منها مرض التيفوس الوبائي الذي تسـببه Rickettisia prowazeki ومرض الحمى الراجعة والذي

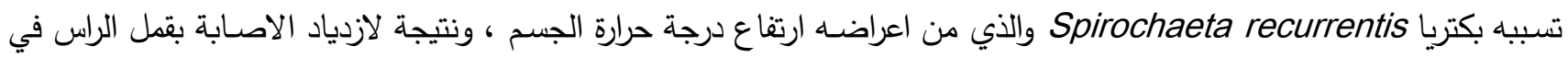

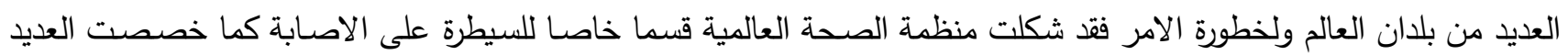

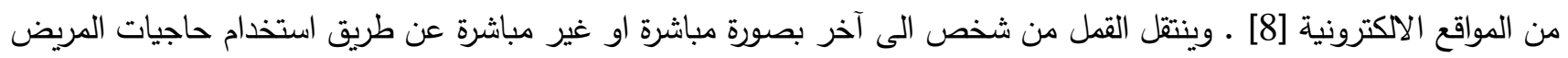

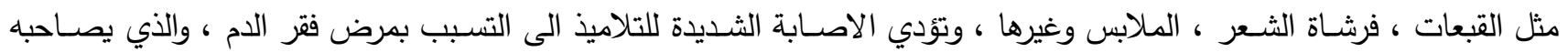

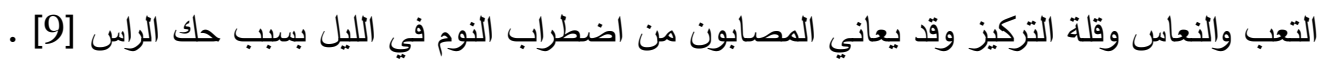
يعد التقعل مرض جلدي شـائع في العراق خصـوصــا في الســوات الاخيرة نتيجة للظروف الراهنة التي اثرت سـلباً على الحالة

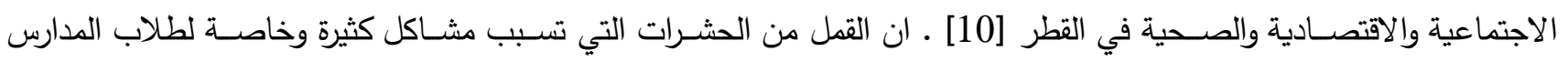
الابتدائية في البلدان النامية [11] ـ وبسبب الاختلاط بين الطلاب وطبيعة انتثار القمل وسرعة حدوث العدوى به فقد اجريت العديد

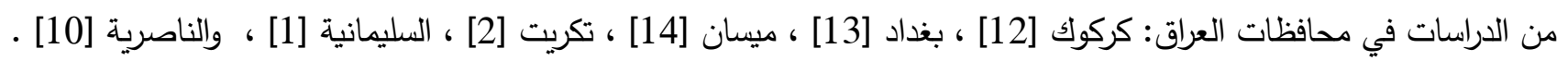
تعد الاصـابة بقمل الراس اكبر مشكلة ليس في الدول الفقيرة فقط بل في الدول المتقدمة والصناعية ايضاً ، حيث يصاب اكثر من

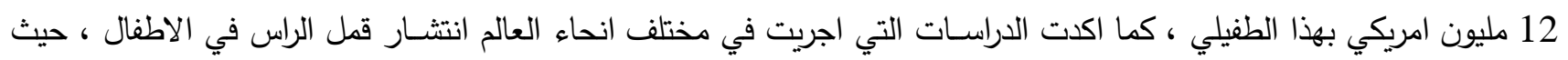

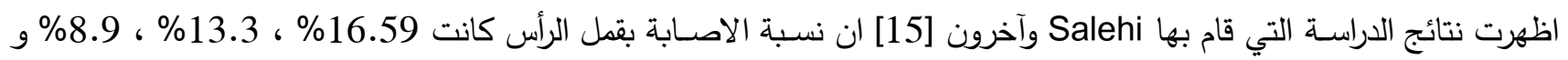
47\% في الهند واليمن وبلجيكا وايران على التوالي • ان الاصـابة بقمل الراس منتشرة عالميا بشكل واسع خاصـة بين طلاب الددارس الابتدائية والصم والعميان [11] ، فقد سجلت في

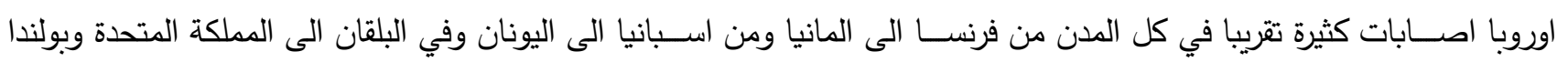


ان معالجة هذه الاصـــابة تختلف حسـبـ الدول ، وتعد الثــامبوات من المواد العلاجية لكنها ذات فعالية قليلة وذلك لنقص فترة التماس مع فروة الراس ، وايضــا اسـتخدام المبيدات الحثـرية المالاثيوم او البيريثرين موضـعيا يقضسي على القمل ، كما يجب ازالة

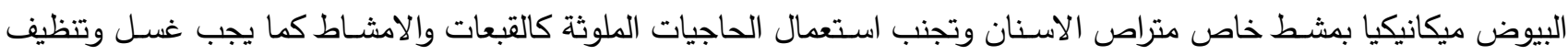

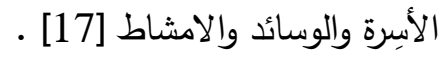

الهدف من دراسـتنا الحالية هو نقل صـورة واقعية الى الجهات الصـحية المعنية للحد من هذه الاصــابة الطفيلية او التقليل منها

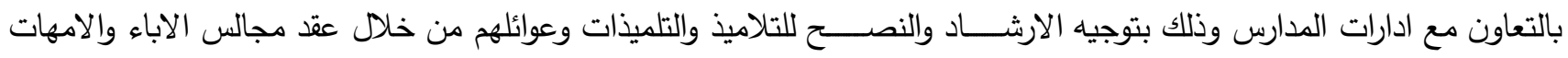

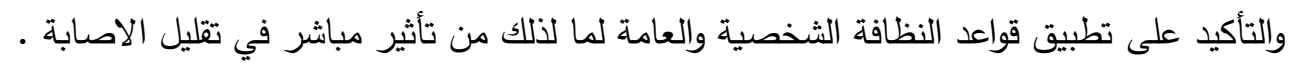

المواد وطرق العمل

تم في الدراسة الحالية التحري عن نسب انتشار قمل الرأس في احدى عشرة مدرسة ابتدائية من ثمان مناطق متباينة في المستوى المعاشي والاقتصادي والثقافي في مدينة الموصل بجانبيها الايسر والايمن والمناطق هي (حي الجزائر ، حي فلسطين، حي المثنى) في تمني

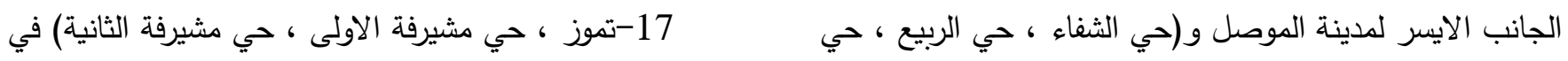
الجانب الايمن لمدينة الموصل خلال الفترة (15 تشرين الاول 2018 ولغاية 15 شباط 2019)، وشملت الدراسة 5636 تلميذة كانت أعمارهم بين (6-12) سنة.

أجري الفحص العيني الخارجي المباشر لرؤوس التلميذات ، حيث تم فحص فروة الرأس مع تركيز الاهتمام على منطقتين هما القفا (مؤخرة الرأس) وخلف الأذنين إذ أن القمل يفضل تلك المناطق [18]، واجري الفحص بالعين المجردة مع استخدام العدسة المكبرة عند الحاجة، وتم تثخيص الإصابة عند وجود الحشرة كاملة (ولو بصعوبة لسرعتها) أو أحد أطوارها (بيضة أو حورية) (الثكل 4)، تم عد الثردين

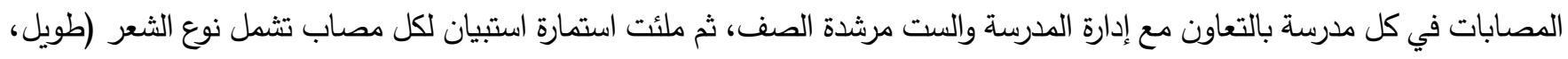
قصير)، وقسم الثعر في الإناث إلى مجموعتين، الأولى الثعر الطويل يتجاوز الكتثين والثانية الثعر القصير يلامس الكتفين، كما شملت الاستمارة على المستوى التعليمي للأم (متعلمة، غير متعلمة) وأيضا عدد أفراد الأسرة (أقل من 5 أفراد، أكثر من 5 أفراد)، ولقد قمنا

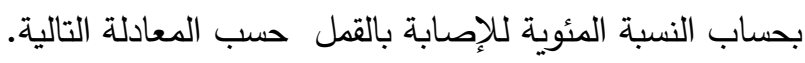
النسبة المئوية (\%) = (عدد الطالبات المصابات بالقمل) / العدد الكلي للطالبات في المدرسة) × 100 


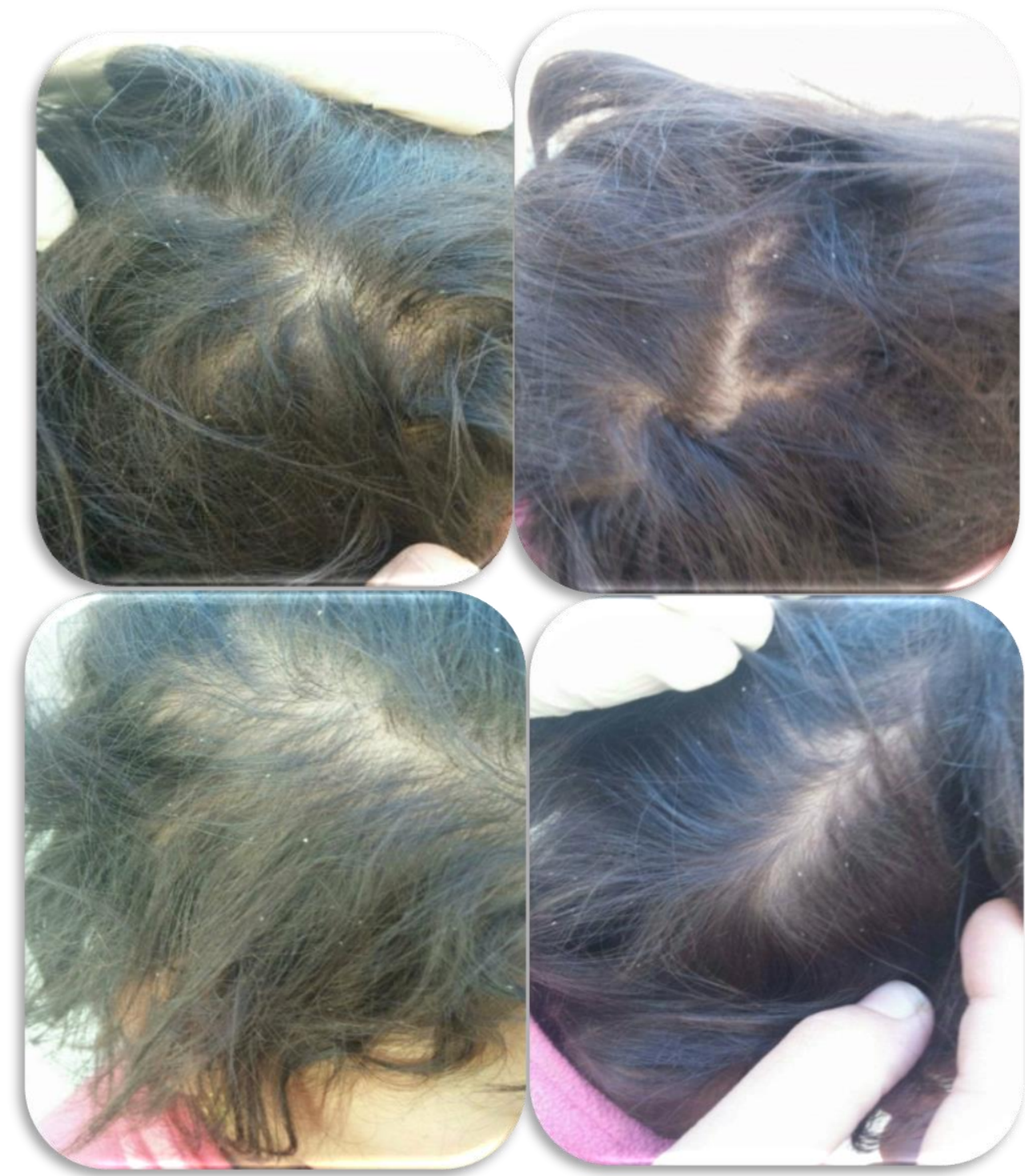

الثكل (3) نماذج من الإصابات بقمل الرأس في المدارس المشمولة بالدراسة

\section{النتائج والمناقثة}

بعد اجراء الفحص العيني على 2469 تلميذة من مدارس الجانب الاييــر و 3170 تلميذة من مدارس الجانب الايمن (المدارس

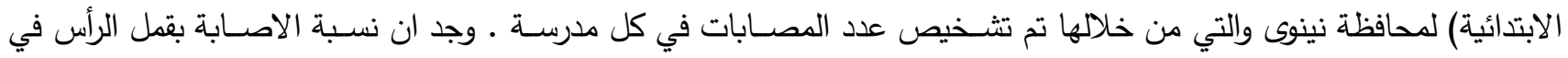

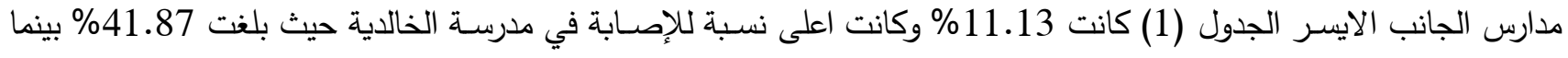
كانت اقل نسبة اصابة في مدرسة زبيدة الاولى وبلغت 2.99\% 


\begin{tabular}{|c|c|c|c|c|c|}
\hline (\%) للمصابين & عدد المصابين & العدد الكلي & اسم المنطقة & اسم المدرسة & ت \\
\hline 2.99 & 16 & 534 & حي الجزائر & زبيدة الاولى & 1 \\
\hline 5.12 & 20 & 390 & حي الجزائر & الجحافل & 2 \\
\hline 41.87 & 67 & 160 & حي الجزائر & الخالدية & 3 \\
\hline 3.28 & 12 & 365 & حي الجزائر & الجنين & 4 \\
\hline 10.0 & 60 & 600 & حي فلسطين & الفراتين & 5 \\
\hline 23.80 & 100 & 420 & حي المثنى & المثنى & 6 \\
\hline المعدل \% & المجموع الكلي & المجموع الكلي & & & \\
\hline 11.13 & 275 & 2469 & & & \\
\hline
\end{tabular}

تبين نتائج الجدول (2) ان نسبة الاصابة بقمل الرأس في مدارس الجانب الايمن كانت 27.44\% وكانت اعلى نسبة للإصابة في مدرسة الكنوز المختلطة حيث بلغت 50\%بينما كانت اقل نسبة اصابة في مدرسة البثائر للبنات حيث بلغت 20.97\% . الجدول (2): المدارس المشمولة بالدراسة في الجانب الايمن

\begin{tabular}{|c|c|c|c|c|c|}
\hline (\%) للمصابين & عدد المصابين & العدد الكلي & اسم المنطقة & اسم المدرسة & $ت$ \\
\hline 23.07 & 150 & 650 & حي الثفاء & الثهيد سالم حسين & 1 \\
\hline 20.97 & 150 & 715 & حي الربيع & البشائر للبنات & 2 \\
\hline 21.81 & 120 & 550 & تموز-17 & الولاء للبنات & 3 \\
\hline 50 & 250 & 500 & مشيرفة الاولى & الكنوز المختلطة & 4 \\
\hline 26.49 & 200 & 755 & مشيرفة الثانية & الساجدين & 5 \\
\hline المعدل \% 27.44 & المجموع الكلي & المجموع الكلي & & & \\
\hline
\end{tabular}

تتفق نتائج الدراســـة الحالية لمدارس الجانب الايســر مع ما ذكره Al-Samarrai and Kadir [19] في وجود نســبة اصـــابة 15.29\% في المدارس الابتدائية في سـامراء • بينما نتائج هذه الدراسـة كانت اقل بكثير مما سجله Al-Kubiassy and Abdul

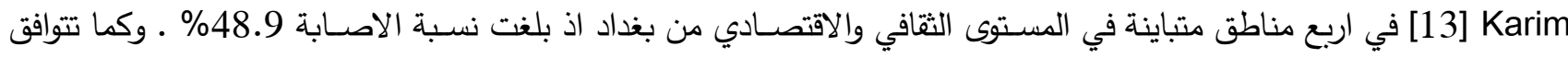

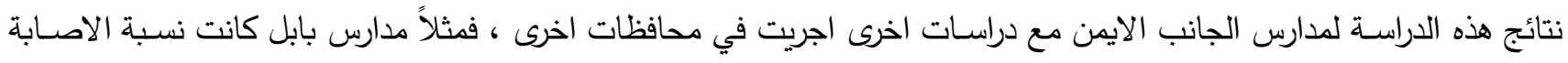

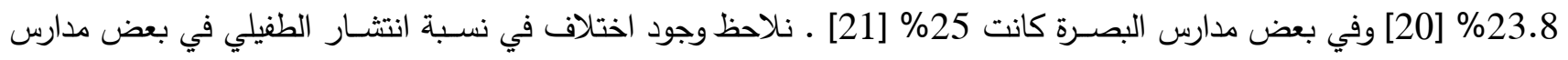
بغداد حيث بلغت 42.2\% [22] ، وهذا التباين في النسـب بالنسـبة لدحافظات القطر يرجع الى الاختلاف في المسـتوى الاجتماعي

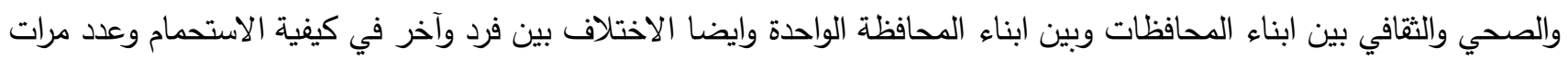

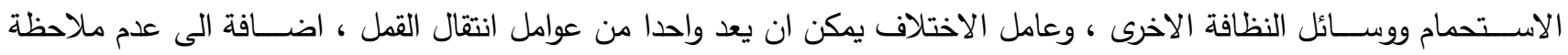

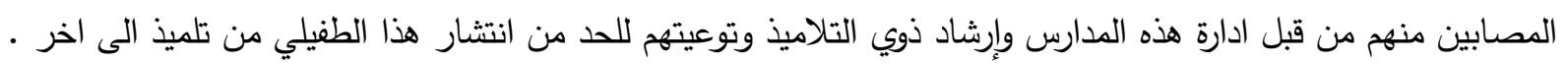
ويتضـح من الجدول (1) ان عدد المصـابين في الجانب الايمن اكثر من الجانب الايسر حيث بلغ عدد المصـابين 870 وبنسبة 27.44\% مقارنة مع الجانب الايسـر الجدول (2) حيث بلغ العدد 275 وبنسـبة 11.13\% يعود السـبب الى ان هذه المناطق فقيرة 
صحيا واقتصساديا وذات كثافة سكانية عالية حيث تقل سبل النظافة بما في ذلك قلة عدد مرات الاستحمام وذلك بسبب قلة الخدمات

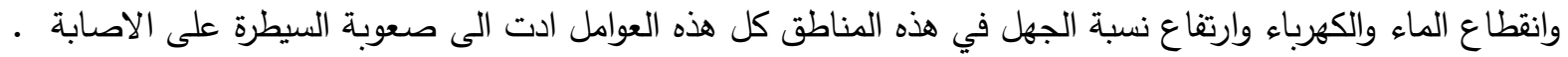

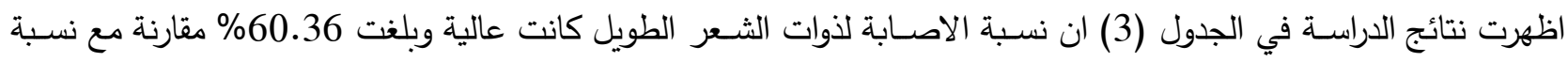

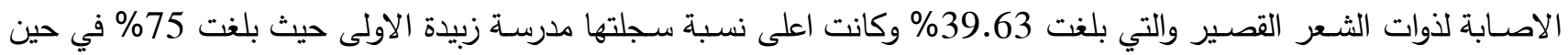
بلغت اقل نسبة اصابة 25\% في مدرسة جنين • في حين كانت اعلى نسبة اصابة لذو الثعر القصير في مدرسة جنين حيث بلغت 75\% وكانت اقل نسبة اصابة 25\% في مدرسة زبيدة الاولى •

الجدول(3): النسبة المئوية للإصابة بقمل الزاس حسب طول الثعر في المدارس المثمولة بالدراسة (الجانب الايسر)

\begin{tabular}{|c|c|c|c|c|c|c|}
\hline \multicolumn{2}{|c|}{ المصابات } & \multicolumn{2}{|c|}{ المصابات } & \multirow{2}{*}{ عدد المصابات } & \multirow{2}{*}{ اسم المدرسة } & \multirow{2}{*}{$ت$} \\
\hline$\%$ & قصيري الثعر & $\%$ & طويلي الثعر & & & \\
\hline 25 & 4 & 75 & 12 & 16 & زبيدة الاولى & 1 \\
\hline 35 & 7 & 65 & 13 & 20 & الجحافل & 2 \\
\hline 29.85 & 20 & 70.14 & 47 & 67 & الخالدية & 3 \\
\hline 75 & 9 & 25 & 3 & 12 & الجنين & 4 \\
\hline 45 & 27 & 55 & 33 & 60 & الفراتين & 5 \\
\hline 42 & 42 & 58 & 58 & 100 & المشى & 6 \\
\hline 39.63 & 109 & 60.36 & 166 & 275 & موع الكلي & \\
\hline
\end{tabular}

تظهر نتائج الجدول (4) النسبة المئوية للإصابة بقمل الراس حسب طول الثعر في المدارس المشمولة بالدراسة (الجانب الايمن) ان

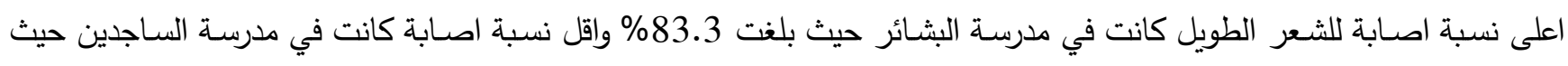
بلغت 66.5\% .

الجدول(4): النسبة المئوية للإصابة بقمل الراس حسب طول الثعر في مدارس (الجانب الايمن)

\begin{tabular}{|c|c|c|c|c|c|c|}
\hline \multicolumn{2}{|c|}{ المصابات } & \multicolumn{2}{|c|}{ المصابات } & \multirow{2}{*}{ عدد المصابات } & \multirow{2}{*}{ اسم المدرسة } & \multirow{2}{*}{ ت } \\
\hline$\%$ & قصيري الثعر & $\%$ & طويلي الثعر & & & \\
\hline 33.33 & 50 & 66.66 & 100 & 150 & الثهيد سالم حسين & 1 \\
\hline 16.66 & 25 & 83.33 & 125 & 150 & البشائر للبنات & 2 \\
\hline 29.16 & 35 & 70.83 & 85 & 120 & الولاء للبنات & 3 \\
\hline 26 & 65 & 74 & 185 & 250 & الكنوز المختلطة & 4 \\
\hline 33.5 & 67 & 66.5 & 133 & 200 & الساجدين & 5 \\
\hline 27.81 & 242 & 72.18 & 628 & 870 & مجموع الكلي & \\
\hline
\end{tabular}

وتتسـجم نتائج هذه الدراســة مع ما توصـل اليه Al-Kubiassy وآخرون [22] من ان الاصــابة بقمل الراس تزداد بزيادة طول الثـعر ، اذ يعمل الثـعر الطويل على توفير متسـع اكثر للقمل مقارنة مع الثـعر القصـير وكذلك طريقة تنظيف وتغلغل المادة المنظفة يكون اسـكل بالثـعر القصسير [23] . وحسـب النتائج التي توصـل اليها (2) لم يظهر لطول الثـعر الاثر الكبير في نسبة انتشار القمل حيث كان الفرق بين نسبتي انتشار القمل في كل من الثعر الطويل والقصير بسيطا جدا ، بينما اظهرت النتائج التي اجريت في المحافظات الاخرى فرق واضـح بين النسبتين (اي ان نسبة انتشار القمل في ذوات الثعر الطويل اعلى من نسبة انتشار القمل في ذوات الثعر القصير ) [24,25]. 
تظهر نتائج الجدول (5) ان نســبة الاصــابة بالقمل للتلميذات ذوات الامهات غير المتعلمات لمدارس الجانب الايسـر قد بلغت 57.45\% وكانت اعلى نسـبة اصـابة سـجلت في مدرسـة الجحافل حيث بلغت 100\% لذوات الامهات الغير متعلمات بينما كانت اعلى نسبة اصابة لذوات الامهات المتعلمات في مدرسة الفراتين حيث بلغت 68.33\% مابهات

الجدول(5): النسبة المئوية للإصابة حسب المستوى التعليمي للام في مدارس الجانب الايسر

\begin{tabular}{|c|c|c|c|c|c|c|}
\hline$\%$ & المصابات من امهات غير & $\%$ & $\begin{array}{c}\text { المصابات من امهات } \\
\text { متعلمات }\end{array}$ & المصابات & اسم المدرسة & ت \\
\hline 93.75 & 15 & 6.25 & 1 & 16 & زبيدة الاولى & 1 \\
\hline 100 & 20 & 0 & 0 & 20 & الجحافل & 2 \\
\hline 89.55 & 60 & 10.44 & 7 & 67 & الخالدية & 3 \\
\hline 91.66 & 11 & 8.33 & 1 & 12 & الجنين & 4 \\
\hline 31.66 & 19 & 68.33 & 41 & 60 & الفراتين & 5 \\
\hline 33 & 33 & 67 & 67 & 100 & المثنى & 6 \\
\hline 57.45 & 158 & 42.54 & 117 & 275 & \multicolumn{2}{|c|}{ المجموع الكلي } \\
\hline
\end{tabular}

تبين نتائج الجدول (6) ان نسـبة الاصــابة بالقمل للتلميذات ذوات الامهات غير المتعلمات في الجانب الايمن بلغت 92.98\% وحصلت مدرسة البثائر على اعلى نسبة حيث بلغت 96\% واقل نسبة اصـابة كانت في مدرسة الساجدين حيث بلغت 86\% بينما كانت اعلى نسبة اصـابة لذوات الامهات المتعلمات سجلتها مدرسـة السـاجدين حيث بلغت 14\% واقل نسبة اصـابة سجلتها مدرسـة

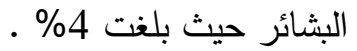

الجدول(6): النسبة المئوية للإصابة حسب المستوى التعليمي للام في مدارس الجانب الايمن

\begin{tabular}{|c|c|c|c|c|c|c|}
\hline$\%$ & المصابات من امهات غير & $\%$ & $\begin{array}{c}\text { المصابات من امهات } \\
\text { متعلمات }\end{array}$ & المصابات & اسم المدرسة & $ت$ \\
\hline 94 & 141 & 6 & 9 & 150 & الثهيد سالم حسين & 1 \\
\hline 96 & 144 & 4 & 6 & 150 & البشائر للبنات & 2 \\
\hline 94.16 & 113 & 5.83 & 7 & 120 & الولاء للبنات & 3 \\
\hline 95.6 & 239 & 4.4 & 11 & 250 & الكنوز المختلطة & 4 \\
\hline 86 & 172 & 14 & 28 & 200 & الساجدين & 5 \\
\hline 92.98 & 809 & 7.01 & 61 & 870 & المجموع الكلي & \\
\hline
\end{tabular}

وتتقق نتائج دراستنا مع Hamad [24] حيث وجد بأن هناك علاقة معنوية بين نسبة الاصـابة بالقمل مع التحصيل الدراسي لكل من الاب والام. كما تتسجم نتائج الدراسة الحالية مع ما توصل اليه karwan and Fouad [26] في وجود ترابط معنوي بين نسبة Maky and الاصـــابة بالقعل والمســتوى التعليمي للعائلة في المدارس الابتدائية في محافظة اربيل .وتتلاءم نتائجنا مع ما ذكره [27 Darweesh بان نسبة الاصابة بقمل الرأس تزداد لاى التلاميذ الذين ابائهم غير متعلمين • وذلك لان الاباء المتعلمين يقومون بحث ابنائهم على الاهتمام بالنظافة الثخصية والالتزام بقواعد الصحة العامة لما لها من اثر كبير في الحد من انتشار الاصابة بقمل الراس لدى التلميذات مقارنة بالآباء غير المتعلمين الذين لا يمتلكون وعي ثقافي لمنع حصول الاصابة لذا تفشت الاصابة بين ابنائها 


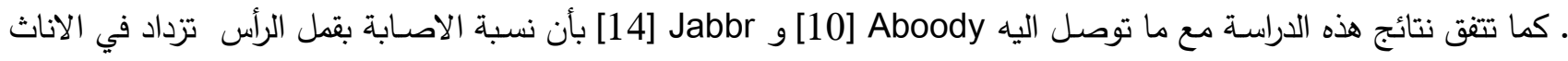
ذوات ابوين غير متعلمين مقارنة بالإناث ذوات ابوين متعلمين •

يتضـح من استعراض النتائج في الجدول (7) ان زيادة عدد افراد الاسـرة اكثر من 5 أفراد ذو تأثير على نسبة الاصـابة مقارنة مع الاسـر التي تكون عدد افرادها اقل من 5 أفراد. حيث بلغت نسـبة الاصــابة بالقمل للتلميذات ذوات الأسـر الاكثر من 5 أفراد لمدارس الجانب الايسر 54.54\% بينما بلغت نسبة الاصـابة للأسر الاقل من 5 أفراد 45.45\% وتميزت مدرسـة الخالدية بأعلى نسبة اصـابة للتلميذات ذوات الاسرة الاكثر من 5 أفراد حيث بلغت 85.07\% وأقل نسبة إصـابة كانت في مدرسـة الفراتين وبلغت

الجدول(7): النسبة المئويـة حسب عدد افراد العائلة في مدارس الجانب الايسر في الموصل

\begin{tabular}{|c|c|c|c|c|c|c|}
\hline$\%$ & المصابات من اسرة أكثر 5 افراد 5 المر & $\%$ & 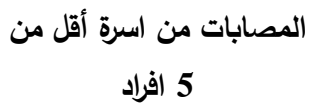 & المصابات & اسم المدرسة & ت \\
\hline 62.5 & 10 & 37.5 & 6 & 16 & زبيدة الاولى & 1 \\
\hline 80 & 16 & 20 & 4 & 20 & الجحافل & 2 \\
\hline 85.07 & 57 & 14.92 & 10 & 67 & الخالدية & 3 \\
\hline 83.33 & 10 & 16.66 & 2 & 12 & جنين & 4 \\
\hline 35 & 21 & 65 & 39 & 60 & الفراتين & 5 \\
\hline 36 & 36 & 64 & 64 & 100 & المثنى & 6 \\
\hline 54.54 & 150 & 45.45 & 125 & 275 & موع الكلي & \\
\hline
\end{tabular}

تبين نتائج الجدول (8) ان نسبة الاصـابة بقمل الرأس للتلميذات ذوات الأسر الاكثر من 5 أفراد لمدارس الجانب الايمن بلغت 77.7

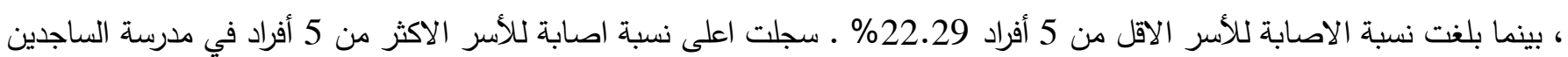

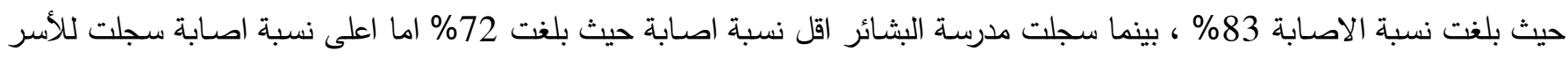
اقل من 5 أفراد فكانت من حصـة مدرسة البشائر والتي بلغت 28\% الاصن اما اقل اصـابة للأسر اقل من 5 أفراد فقد سجلتها مدرسة الساجدين

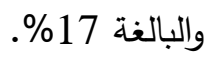

الجدول(8): النسبة المئوية حسب عدد افراد العائلة في مدارس الجانب الايمن في الموصل

\begin{tabular}{|c|c|c|c|c|c|c|}
\hline$\%$ & المصابات من اسرة أكثر 5 افراد 5 & $\%$ & المصابات من اسرة أقل من 5 & المصابات & اسم المدرسة & ت \\
\hline 76.66 & 115 & 23.33 & 35 & 150 & الشهيد سالم حسين & 1 \\
\hline 72 & 108 & 28 & 42 & 150 & البشائر للبنات & 2 \\
\hline 76.66 & 92 & 23.33 & 28 & 120 & الولاء للبنات & 3 \\
\hline 78 & 195 & 22 & 55 & 250 & الكنوز المختطة & 4 \\
\hline 83 & 166 & 17 & 34 & 200 & الساجدين & 5 \\
\hline 77.7 & 676 & 22.29 & 194 & 870 & لمجموع الكلي & \\
\hline
\end{tabular}




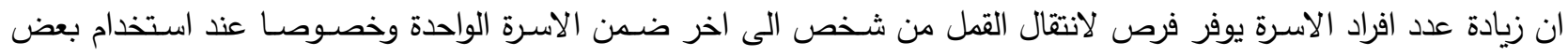

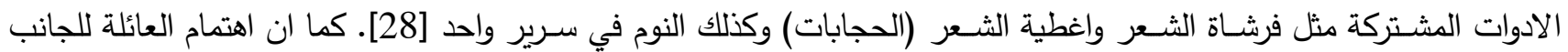
الغذائي (المعاشي) واهمال الجانب الخدمي والصحي بسبب الظروف التي عاشتها المدينة في الثلاث سنوات الاخيرة ادى الى انتشار

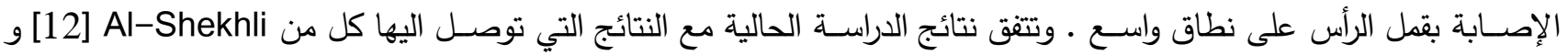

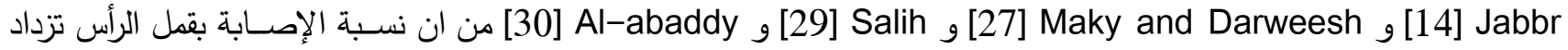

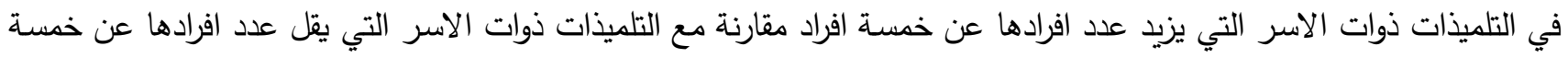

1. Ali F.M and Hama A.A., Iraqi J. sci., 59(2c): 1012-1018 (2018).

2. . Al-Alousi T.I. and . Tawfeeq A.E. Tikrit J. Pure Sci 14(1):240-244 (2009) .

3. Molan A.; Faraj A.M. and Hiday A.M., "Practical medical Entomology" 1st Ed. Dar Erbil -printing and puplishing (2012).

4. Resh V.H. and Carde R.T. "Encyclopedia Of Insects" 1st Ed.. Academic Press (An imprint of Elsevier Science), San Diego, California, USA. (2003).

5.Hassan H.F. and Hayder A.A. "Practical parasitology (Medical Entomology)"Fatholy Kirkuk, Iraq (2014) .

6. Shorab H. "Principles of Medical and Veterinary Entomology" Academic Library, Cairo Egypt (2013) .

7. Al-Marjan K.S.N. and Kamil F.H. Al-Mustansiriyah J.Sci. 25(2) (2014) .

8. Suleiman A.K. and Magar E.A. Tikrit J. Pure Sci 6(19):1-6 (2014) .

9. Mahmood S.A. Iraqi J.sci. 51(1):49-55 (2010).

10. Aboody B.A. Baghdad Sci. J. 5(2):207-210 (2008) .

11. Hunter J.A. and Barker S.C. Parasitol. Res. 90: 476-478 (2003).

12. Al-Shekhli Kh. M.sc. Thesis College of Science, university of Tikrit (2009) .

13. Al-Kubiassy W. and Abdul Karim E .T., J. Bahrain Med. Soc., 15: 34-38 (2003) .

14. Jabbr A.K., J. Mesan Rese. 1(2):191-206 (2005) .

15. Salehi S.h. ; Ban M. and Motaghi M. Int.J.Comm.Bas.Nur.Midw. 2(3):196-200 (2014) .

16. Sidoti E. ; Bonura F. and Paolini G., J. Prev. Medi. Hyg. 50(3): 141-151 (2009).

17. Bodor R. Tishreen Univ .J. Res. Sci. Stu.s - Heal. Sci. Series 33 (5): 2011 . 
18. Service M.W. "Lice Corder Anoplura: Families Pediculidae and Phthiridae. In :A guide to medical entomology" 1st Ed. Mac Millan Press Ltd. London (1980).

19. Al-Samarrai R.J. and Kadir M.A. Med.J. Tikrit Univ. 6:47-51 (2000).

20. Al-Khafaji A.H., M.sc. Thesis College of science university of Babylon (1999) .

21. Affas N.H. , J. Comm. Med. 6(1):37-44 .

22. Al-Kubiassy W. A. ; Al-Rawi J. R and Al-Rubae M. G., J. Fac. Med. Baghdad, 36(4):665-670 (1994) .

23. Schmidt G. D. and Roberts L. S. "Foundations of parasitology" 4th Ed., Times Mirror , Mosby Coll., Publ., Saint Louis (1989).

24. Hamad S.H. , Tikrit J. Pure Sci 10(1):36-40 (2005) .

25. Abas E.M., M.sc. Thesis College of Education Ibn Al Haitham , university of Baghdad (1997) .

26. Karwan S. N. and Fouad H. K. Al-Mustansiriyah J.Sci. Baghdad- Iraq. 25(2) (2014) .

27. Maky A.H. and Darweesh S., J. kerbala univ. 2(5):276-279 (2007) .

28. Mohammed A. , Dawood S. A., Kadir M.A. and Al-Sheikhly K. T., Tikrit J. Pure Sci. 3(17):7-11 (2012) .

29. Salih W.M., J. kerbala univ. 8(1):334-339 (2010) .

30. Al-abaddy A.I., Tikrit J. Pure Sci 14(2):153-159 (2009) . 